\section{Passive Movements in Perspective}

\section{J. RUNNALLS*}

Although passive movements form an integral part of physiotherapy techniques, and have been used by physiotherapists for as long as physiotherapy has existed, the approach to passive movements has, the author feels, been somewhat haphazard and incomplete. Both physiotherapists and physiotherapy students are probably a bit confused, and the author will therefore endeavour to clarify the various types of passive movements with reference to their specific application as seems laudible to her.

The classic definition of passive movement reads as follows: "Movement which is produced by an external force, during muscular inactivity or when the latter is voluntarily reduced as much as possible to permit movement." (Gardiner 1973, p. 70). ${ }^{1}$

The range of movement of a joint delineates the amount of movement of a particular joint which takes place in a particular plane. The amount of movement available is dependant upon age, hyper- or hypomobility or any joint pathology. The range of movement maybe diagramatically represented (Fig. 1) as follows:

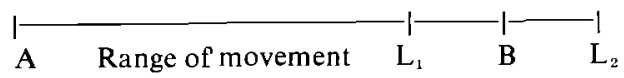

$A=$ Beginning of range

$B=$ Average limit of range

$\mathrm{L}_{1}=$ Limit of range of hypomobile joint

$\mathrm{L}_{2}=$ Limit of range of hypermobile joint

Fig. I

Passive movements may extend throughout the range of movement or may be given in various parts of the range of movement. A useful method of describing the part of the range being used for treatment has been propagated by G. D. Maitland. (Maitland, 1970 p. 22). ${ }^{2}$ The various parts of the range being diagrammatically represented as follows:

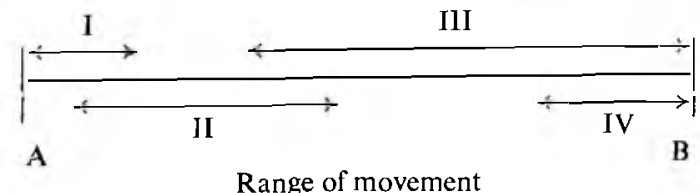

Fig. II

Grade I: Small amplitude movement at the beginning of the range.

Grade II: Large amplitude movement performed within the range, but not reaching the limit of the range.

Grade III: Large amplitude movement performed up to the limit of the range.

Grade IV: Small amplitude performed at the limit of the range.

- Senior Lecturer: Head Department of Physiotherapy, University of Stellenbosch and Tygerberg Hospital, Tiervlei.

Article received March. 1975.
If the normal range of joint movement is limited by pathology, Grades III and IV are restricted to the new limit of the range, and Grade II movements are re stricted to smaller amplitudes. (Fig. 111) (Maitland, 1970 p. 23). ${ }^{3}$
I

Fig. III

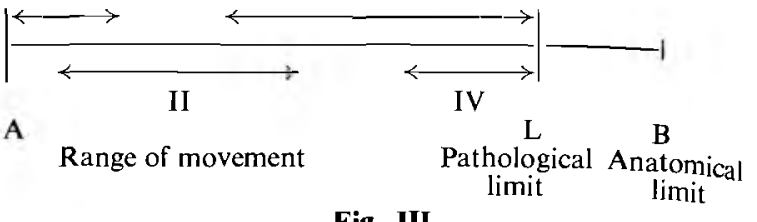

Classification of passive movements.

(1) Physiological passive movements: The total range of physiological passive movements is more or less the same as the comparable range of active movement, the joint surface relationship is however no always the same. Muscles contract during actif movements with resultant joint compression and gliding movements. Unless compression is specifically applied during passive movements the joint surface apposition may not be identical.

(2) Accessory passive movements: These are small movements which are not under muscle control and are brought about in various parts of the range by the use of the thumb or pressure of the hand. It is impossible for the patient to do these movements voluntarily. (Maitland, 1970 p. 4). ${ }^{*}$ Accessory movements have been further categorized in Gray's Anatomy as follows: "The movements which can be performed actively at any joint do not necessarily include all the movements which the structure of the joint would permit. Certain movements which cannot be performed voluntarily can nevertheless be produced when resistance is encountered to active movements (accessory movements, first type), e.g. it is only when some solid object, such as a cricket ball, is grasped in the hand, that fingers can be rotated at the metacarpo-phalangeal joints. Other movements can only be produced passively (accessory movements, second type) and their widest range is obtained when the muscles acting on the joint are fully relaxed, e.g. when the arm is partially abducted at the shoulder joint, the humerus can bs drawn away from the glenoid cavity. Such movf ments are commonly termed "passive movements" but as all the movements whether active or not car be performed passively when the muscles concernec are relaxed, the term accessory movements will bc used to designate all movements which cannot be performed actively in the absence of resistance." (Davies, 1967 p. 492). ${ }^{5}$

Modalities of passive movements.

(1) Relaxed - the joints are moved throughout or through part of their range in either (i) a rhythmic or (ii) an oscillatory manner.

(2) Forced -

(i) A smooth sustained stretch is maintained at the end of the range. Furthermore, a single sustained stretch may be forced past the end of the existing range; this may be regarded as a manipulation.

(ii) A small oscillatory movement is maintained at the end of the range.

(iii) A manipulation, a small, quick movement with a controlled amount of force, is performed at the end of the available range. 
The uses of passive movements.

(I) To maintain and improve the circulation.

The venous circulation is aided by passive movement especially when the veins and the lymphatics are influenced by the surrounding muscles and fascia. (Leffelaar, 1971, p. 96). ${ }^{6}$ For the purposes of the maintenance and the improvement of circulation, passive physiological movements should be applied rhythmically at a gentle tempo so as to enable time for the mechanical effects of the movements to be established. (Leffelaar, 1971, p. 97). ${ }^{\top}$ The movements should be done ten times in each direction and ideally three times a day. (Guttman, 1973, p. 535$){ }^{8}$

\section{Precautions.}

(a) If these movements are done too vigorously and too deep into the range, especially as regards hip flexion and extension pertaining to treatment of paraplegics, para-articular ossification will be facilitated. (Guttman, 1973, p. 535). ${ }^{\circ}$

(b) Dorsiflexion of the ankle must be performed to its full range with the knee in extension to be effective in the prevention of deep vein thrombosis.

(2) To improve joint nutrition.

It is theorized that passive movements which improve the circulation will indirectly also improve the joint nutrition by means of improved blood supply to the joint. It is probable that the overpressure and traction used in effecting passive movements exhibit a suction pump action on the vessels which supply the joint.

(3) To induce relaxation.

Gentle passive physiological movement encourages the local relaxation of "protective" muscle spasm. It is however important to remember that treating the protective muscle spasm is not truly the answer. The underlying pathology which causes the muscle to go into spasm should be treated. For example, protective muscle spasm of the trapezius is approached far more scientifically by treating the vertebral component with passive intervertebral accessory movements at the appropriate level.

(4) To prevent contractures and adhesions and to maintain joint range.

The adaptive shortening of joint structures and especially the two-joint muscles. (Basmasjian, 1967, p. 128 $)^{10}$ are of particular importance. As regards the structures surrounding the joints, physiological passive movements from the full close-pack position to the full loose-pack position are of primary functional importance (Twomey, 1974, p. 172) ${ }^{11}$ and should be given with the necessary traction and overpressure. Two-joint muscles require two fully maintained stretches per day.

\section{Precautions:}

The starting position is of cardinal importance for efficiency of technique. For example, in the case of a flaccid paralysis the contralateral hip should be positioned in full flexion and the ipsilateral knee should be held in flexion for ipsilateral hip extension effecting full stretch on the rectus femoris. With reference to spastic paralysis the position of the head and neck are absolutes for effective treatment. The labyrinth and tonic neck reflexes influence the muscle tone which under no circumstances must be allowed to increase.

(5) To inprove joint range.

When capsular involvement prevents the full range of movement there are various ways in which the range may be improved. A manipulation, a small range forced passive movement, may be performed or an oscillatory full stretch small range movement may be maintained at the end of the range (Grade $1 \mathrm{~V}$ movement). This oscillatory movement could be either a passive physiological or passive accessory movement. (Maitland, 1973, p. 65). ${ }^{12}$ When joint range is limited by muscle shortening a passive physiological movement is maintained at the end of the available range.

Precaution:

For both Grade IV movements and manipulation an accurate and full subjective and objective examination is an absolute pre-requisite for treatment.

(6) To maintain the memory pattern of movement and to provide normal sensori-motor experience. When paralysis ensues passive physiological movements are performed to maintain the memory pattern of movement. The kinaesthetic receptors are thus constantly stimulated by these movements. Passive physiological movements are further given to children with a disturbance of movement so that they can obtain an appreciation of the normal sensori-motor experience.

(7) To relieve pain.

The use of passive movement in the treatment of pain as distinct from treating stiffness is becoming increasingly more important. Pain is relieved by oscillatory relaxed passive movements, Grades I and II with the joint in the neutral position and passive physiological movements Grades II and III once $50 \%$ of the available active range has been achieved. (Maitland, 1973, p. 67). ${ }^{13}$ One of the possible theories for the relief of pain is the "Gate Control Theory" propagated by Melzack and Wall, 1965 , p. 971. ${ }^{14}$ of course, changes in fluid balance, the blood supply, the pure mechanical effects of passive movements and the "tender loving care" element of passive movements are all possibly reasons for the relief of pain effected by passive movements.

Precaution:

Pain may easily be exacerbated by treatment by passive movement even if the movements are performed in the pain free range. The Gate Control Theory (Melzack and Wall, 1965, p. 971) ${ }^{15}$ is the possible explanation for this phenomenon.

In conclusion, it can be seen that passive movements cannot be given indiscriminately. The physiotherapist must bear in mind the aim of her treatment and then apply the necessary modifications of the various passive movements techniques to accomplish her specific aim.

\section{OPSOMMING:}

Passiewe bewegings is ingedeel en hulle gebruike om die bloedvoorsiening te behou en verbeter, om gewrigsvoeding te verbeter, om ontspanning te veroorsaak, om kontrakture en vasklewings te voorkom, om gewrigsomvang te behou en verbeter, om die geheue-patroon van beweging te behou, om die normale sensorimotoriese ondervinding te voorsien en om pyn te verlig, is bespreek.

\section{ACKNOWLEDGEMENTS:}

Mr. G. D. Maitland, A.U.A., F.C.S.P., M.A.P.A., Parttime Lecturer in Physiotherapy, South Australian Institute of Technology, Adelaide and Miss S. IrwinCarruthers, Nat. Dipl. Physio. (Pta.), Teaching Dip. Physio. (Pta.), Lecturer in Physiotherapy, University of Stellenbosch, for their encouragement and help. 